\title{
Kualitas Layanan Serta Pengaruhnya Terhadap Kepuasan Masyarakat (Studi Tentang Pemanfaat Media Sosial Dan Sms Center Sebagai Sarana Pengaduan Di Dinas PUPR Kota Blitar)
}

\author{
Mujiono, M. Naim Musyafik \\ Magister Manajemen Universitas Islam Kadiri
}

\begin{abstract}
The purpose of this study was to determine the process of handling public complaints through social media and sms center in Blitar City. Testing the significance of the effect of service quality on community satisfaction on social media users and sms center as a means of public complaints in the Office of Public Works and Spatial Planning of Blitar City. Which service quality variable dominantly influences community satisfaction on social media users and sms center as a means of public complaints in the Department of Public Works and Spatial Planning of Blitar City.

The research methodology used descriptive questionnaires, interviews and multiple linear regression tests on 5 (five) independent variables namely tangibles X1, X2 reliability, responsiveness X3, assurance X4 and attention (empathy). ) X5 against $Y$ dependent community satisfaction variable.

The results of the study concluded that the Guarantee, Physical Evidence, Empathy and Responding variables simultaneously (together) had a significant influence on community satisfaction and spatially only the four variables had an influence on community satisfaction.
\end{abstract}

Keywords: social media, SMS center, public complaints, community satisfaction, service quality

\section{LATAR BELAKANG TEORITIS}

\section{Latar belakang masalah}

Kepuasan masyarakat dipengaruhi dua variabel utama, yaitu Expectations dan Perceived Performance, bila Perceived Performance melebihi Expectations, maka konsumen mendapatkan kepuasan, akhirnya akan menciptakan loyalitas konsumen (Tjiptono, 2000 : 41). Ada beberapa faktor yang dapat dipertimbangkan oleh konsumen dalam menilai suatu pelayanan yang diberikan oleh perusahaan. Menurut Zeithaml, Berry dan Parasuraman (1985) dikutip dalam Tjiptono (2000) berhasil mengidentifikasi lima dimensi kualitas jasa, yaitu : (1)Bukti langsung /tangibles; (2) Kehandalan / reliability; (3) Daya tanggap/responsiveness;(4) Jaminan / assurance; (5) Perhatian / emphaty.

\section{Pelayanan Publik}

$\begin{array}{cc} & \text { Pelayanan umum atau pelayanan } \\ \text { publik menurut Wasistiono dalam }\end{array}$ Hardiyansyah (2011:11) adalah pemberian jasa, baik oleh pemerintah, pihak swasta atas nama pemerintah ataupun pihak swasta kepada masyarakat, dengan atau tanpa pembayaran guna memenuhi kebutuhan dan atau kepentingan masyarakat.

Berbeda dengan pendapat di atas, Ratminto dan Winarsih (2005) berpendapat bahwa: "pelayanan public atau pelayanan umum sebagai segala bentuk jasa pelayanan, baik dalam bentuk barang publik maupun jasa publik yang pada prinsipnya menjadi tanggungjawab dan dilaksanakan oleh instansi pemerintah di pusat, di daerah, dan lingkungan Badan Usaha Milik Negara (BUMN) atau Badan Usaha Milik Daerah (BUMD), dalam upaya pemenuhan kebutuhan masyarakat maupun dalam rangka pelaksanaan ketentuan peraturan perundangundangan".

Sedangkan pelayanan umum menurut Moenir (2010:26) adalah kegiatan yang dilakukan oleh seorang atau sekelompok orang dengan landasan faktor materiel melalui sistem, prosedur dan metode tertentu dalam rangka usaha memenuhi kepentingan orang lain sesuai dengan haknya. Sinambela (2011)berpendapat bahwa:

"pelayanan publik adalah pemenuhan keinginan dan kebutuhan masyarakat oleh penyelenggara negara. Negara didirikan oleh publik (masyarakat) tentu saja dengan tujuan agar dapat meningkatkan kesejahteraan masyarakat.

Ciri-ciri Pelayanan Publik

Ciri-ciri pelayanan publikyang baik, dalam hal ini pelayanan bank, menurut Kasmir (2006) adalah memiliki unsur sebagai berikut : 
a) Tersedianya karyawan yang baik.

b) Tersedianya sarana dan prasarana yang baik

c) Bertanggung jawab kepada setiap nasabah (pelanggan) sejak awal hingga akhir.

d) Mampu melayani secara cepat dan tepat

e. Mampu berkomunikasi.

f. Memberikan jaminan kerahasiaan setiap transaksi.

g. Memiliki pengetahuan dan kemampuan tertentu.

h. Berusaha memahami kebutuhan nasabah (pelanggan).

i. Mampu memberikan kepercayaan kepada nasabah (pelanggan).

\section{Klasifikasi Pelayanan Publik}

Menurut Mahmudi dalam Hardiyansyah (2011) pelayanan public yang harus diberikan oleh pemerintah diklasifikasikan ke dalam dua kategori utama, yaitu pelayanan kebutuhan dasar dan pelayanan umum.

\section{Azas-azas Pelayanan public}

Menurut UU No. 25/2009 tentang pelayanan publik, penyelenggaraan pelayanan publik berazaskan: (a) Kepentingan umum, (b)Kepastian hukum, (c) Kesamaan hak, (d)Keseimbangan hak dan kewajiban, (e)Keprofesionalan, (f)Partisipatif, (g) Persamaan perlakuan/tidak diskriminatif, (h)Keterbukan, (i) Akuntabilitas, (j)Fasilitas dan perlakuan khusus bagi kelompok rentan, (k)Ketepatan waktu,

Kecepatan, kemudahan, dan keterjangkauan, Standar Pelayanan Publik

$$
\text { Menurut Peraturan Menteri }
$$

Pendayagunaan Aparatur Negara dan Reformasi Birokrasi Nomor 36 Tahun 2012 tentang Petunjuk Teknis Penyusunan, Penetapan, dan Penerapan Standar Pelayanan, komponen standar pelayanan adalah komponen yang merupakan unsure unsur administrasi dan manajemen yang menjadi bagian dalam sistem dan proses penyelenggaraan pelayanan publik. Berdasakan Bab 5, Pasal 21 UU Nomor 25 Tahun 2009, setiap standar pelayanan dipersyaratkan harus mencantumkan komponen sekurang - kurangnya meliputi (a) Dasar hukum, (b)Persyaratan, (c) Sistem, mekanisme, (d) Jangka waktu penyelesaian, (e) Biaya/tarif, (f) Produk pelayanan, (g)Sarana, prasarana, dan/atau fasilitas,
(h)Kompetensi pelaksana, (i)Penanganan pengaduan, saran dan masukan, (j) Jaminan pelayanan, (k)Jaminan keamanan dan keselamatan pelayanan, (l)Evaluasi kinerja pelaksana.

\section{Kualitas Pelayanan Publik}

Kualitas pelayanan ( Service Quality) seperti yang dikatakan oleh Parasuraman dalam Lupiyoadi (2001) dapat didefinisikan yaitu seberapa jauh perbedaan antara kenyataan dan harapan konsumen atas pelayanan yang mereka terima/peroleh.Menurut Lewis \& Booms dalam Tjiptono \& Chandra (2005), kualitas pelayanan sebagai ukuran seberapa baik tingkat layanan yang diberikan mampu sesuai dengan harapan pelangan.

Sedangkan menurut Ibrahim (2008), pelayanan publik merupakan suatu kondisi dinamis yang berhubungan dengan produk, jasa, manusia, proses dan lingkungan dimana penilaian kualitasnya ditentukan pada saat terjadinya pemberian pelayanan publik tersebut.

Menurut Wyckof dalam Tjiptono (1996)"kualitas pelayanan diartikan sebagai keunggulan yang diharapkan dan pengendalian atas tingkat keunggulan tersebut untuk memenuhi keinginan pelanggan. Kualitas pelayanan bukanlah dilihat dari sudut pandang pihak penyelenggara atau penyedia layanan, melainkan berdasarkan persepsi masyarakat (pelanggan) penerima layanan. Pelangganlah yang mengkonsumsidan merasakan pelayanan yang diberikan, sehingga merekalah yang seharusnya menilai dan menentukan kualitas pelayanan".

Berdasarkan beberapa pendapat di atas, dapat disimpulkan bahwa kepuasan pelanggan adalah pendapat dan penilaian pelanggan setelah membandingkan kinerja pelayanan aparat pelayanan publik (atau hasil) yang dirasakan dengan apa yang diharapkannya, yang dipengaruhi oleh berbagai faktor misalnya kualitas layanan, tanggung jawab petugas pelayanan, sikap petugas pelayanan dan hasil layanan yang diterima oleh masyarakat.

1. Indeks Kepuasan Masyarakat

Kepuasan masyarakat terhadap pelayanan publik ditentukan oleh kualitas layanan dan sejauh mana keinginan dari 
masyarakat dapat terpenuhi oleh penyelenggara pelayanan publik.

Menurut Surat Keputusan Menteri Pendayagunaan Aparatur Negara Nomor 25/M.PAN/2004 tentang Pedoman Umum Penyusunan Indeks kepuasan Masyarakat Unit Pelayanan Instalasi Pemerintah, indeks kepuasan masyarakatadalah data dan informasi tentang tingkat kepuasan masyarakat yang diperoleh dari hasil pengukuran secara kuantitatif dan kualitatif atas pendapat masyarakat dalam memperoleh pelayanan dari aparatur penyelenggara pelayanan publik dengan membandingkan antara harapan dan kebutuhannya.

2. Faktor - faktor yang Mempengaruhi Kepuasan

Faktor - faktor yang berpengaruh terhadap kepuasan pelanggan erat kaitannya dengan dimensi mutu pelayanan, mutu pelayanan yang baik dan adil akan menimbulkan kepuasan, sebaliknya apabila dimensi kualitas pelayanan yang buruk akan menimbulkan ketidakpuasan.

Menurut

Tjiptono

(1996),

ketidakpuasan masyarakat disebabkan oleh faktor Internal dan faktor eksternal. Faktor internal yang relatif dapat dikendalikan instansi/badan, misalnya karyawan yang kasar, jam „karet", kesalahan pencatatan transaksi.

Sebaliknya, faktor eksternalyang di luar kendali instansi/badan, seperti cuaca, gangguan pada infrastruktur umum, aktivitas kriminal, dan masalah pribadi masyarakat sebagai konsumen. Menurut Moenir (2010), agar layanan dapat memuaskan orang atau sekelompok orang yang dilayani, adaempat persyaratan pokok, yaitu: "(1) tingkah laku yang sopan, (2) cara menyampaikan sesuatu yang berkaitan dengan apa yang seharusnya diterima oleh orang yang bersangkutan, (3) waktu penyampaian yang tepat, dan (4) keramah tamahan. Faktor pendukung yang tidak kalah pentingnya dengan kepuasan diantaranya faktor kesadaran para pejabat atau petugas yang berkecimpung dalam pelayanan umum, faktor aturan yang menjadi landasan kerja pelayanan, faktor organisasi yang merupakan alat serta sistem yang memungkinkan berjalannya mekanisme kegiatan pelayanan, faktor pendapatan yang dapat memenuhi kebutuhan hidup minimum, faktor keterampilan petugas, dan faktor sarana dalam pelaksanaan tugas pelayanan. Faktor - faktor tersebut secara umum dapat di uraikan sebagai berikut:

- Kebutuhan dan keinginan berkaitan dengan hal-hal yang dibutuhkan pelanggan. Jika kebutuhannya besar, maka harapan (ekspektasi) masyarakat juga besar.

- Pengalaman masa lalu masyarakat atau konsumen ketika menggunakan jasa atau produk yang sama pada tempat yang sama.

- Cerita dari orang lain yang pernah menggunakan barang/jasa pada tempat yang sama.

- Iklan melalui media massa dapat mempengaruhi kepuasan konsumen atau masyarakat".

3. Mengukur Kepuasan Pelanggan /Masyarakat

Menurut Kotler yang dikutip Tjiptono (1996) terdapat empat metode untuk mengukur kepuasan pelanggan, yaitu sebagai berikut:

1. Sistem keluhan dan saran, artinya setiap instansi/badan yang berorientasi pada pelanggan perlu memberikan kesempatan seluas - luasnya bagi para masyarakat untuk menyampaikan saran, pendapat, dan keluhan mereka. Media yang bisa digunakan meliputi kotak saran yang diletakan di tempat tempat strategis, menyediakan kartu komentar, menyediakan saluran telepon.

2. Survei kepuasan masyarakat, artinya kepuasan dilakukan dengan menggunakan metode survei, baik melaui pos, telepon, maupun wawancara pribadi. Survei ini diharapakan akan memperoleh tanggapan dan umpan balik secara langsung dari masyarakat sekaligus juga memberikan tanda positif bahwa instansi menaruh perhatian terhadap para masyarakat.

3. Ghost shopping, artinya metode ini dilaksanakan dengan cara memperkerjakan beberapa orang (ghost sopper) untuk berperan atau bersikap sebagai pelanggan atau 
pembeli potensialproduk perusahaan dan pesaing. Kemudian ghost soppermenyampaikan temuan temuan mengenai kekuatan dan kelemahan produk perusahaan dan pesaing berdasarkan pengalaman mereka dalam pembelian produk produk tersebut.

4. Lost customer analysis, artinya instansi menghubungi masyarakat yang telah melakukan pelayanan yang diharapakan diperoleh informasi atas kepuasan masyarakat terhadap pelayanan.Tujuan Penelitian

Tujuan umum penelitian ini adalah untuk mengidentifikasi pola hubungan kualitas layanan terhadap kepuasan masyarakat. Sejumlah tujuan khusus yang melandasi dilaksanakannya penelitian ini dirumuskan sebagai berikut:

1. Untuk mengetahui proses penanganan aduan masyarakat melalui media sosial dan sms center di Kota Blitar Menguji signifikansi pengaruh kualitas layanan terhadap kepuasan masyarakat pada pemanfaat media sosial dan sms center sebagai sarana pengaduan masyarakat di Dinas Pekerjaan Umum Dan Penataan Ruang Kota Blitar.

2. Untuk mengidentifikasi variabel kualitas layanan manakah yang dominan mempengaruhi kepuasan masyarakat pada pemanfaat media sosial dan sms center sebagai sarana pengaduan masyarakat di Dinas Pekerjaan Umum Dan Penataan Ruang Kota Blitar.

\section{METODE}

\section{Bagan 1 Kerangka Pikir}

\begin{tabular}{|l|}
\hline Variabel X Kualitas Pelayanan \\
1. Tangibles(Bukti Langsung \\
2. Reability (Kehandalan) \\
3. Responsiveness (Ketanggapan) \\
4. Assurance (Jaminan) \\
5. Emphaty (Empati) \\
\hline
\end{tabular}

Teknik Pengambilan Sampel

Teknik Pengambilan Sampel dalam penelitian ini menggunakan sampling aksidental (Accidental sampling) adalah teknik penentuan sampel berdasarkan kebetulan, yaitu siapa saja yang secara kebetulan bertemu dengan peneliti dapat digunakan sebagai sampel, bila dipandang orang yang kebetulan ditemui itu cocok sebagai sumber data (Sugiyono, 1999).

\section{Teknik Pengumpulan Data}

Untuk memperoleh data dan informasi yang diperlukan dalam penelitian ini, digunakan beberapa metode antara lain :

\section{- Kuesioner}

Kuesioner yaitu membuat daftar pertanyaan untuk diisi oleh responden yang dipilih untuk diselidiki atau sebagai sampel.

- Studi Kepustakaan

\section{Variabel Y}

Tingkat Kepuasan Masyarakat

1. Availability of Service (Keberadaan Pelayanan)

2. Responsiveness of Service (Ketanggapan Pelayanan)

3. Timeliness of Service (Jangka Waktu Pelayanan)

4. Professionalism of Service (Profesionalisme Pelayanan)
Studi kepustakaan yaitu mempelajari buku-buku literatur dan bacaan-bacaan lain yang dapat membantu dalam pemecahan masalah.

\section{- Wawancara}

Untuk mendapatkan data primer Dinas Pekerjaan Umum Dan Penataan Ruang Kota Blitar dilakukan melalui wawancara secara langsung dengan pemimpin Dinas Pekerjaan Umum Dan Penataan Ruang Kota Blitar.

\section{Variabel Penelitian}

Untuk pengukuran variabel dari masing-masing bagian dapat dikategorikan dalam beberapa variabel kualitas layanan yang dapat dibagi dalam lima dimensi yaitu (Parasuraman et. al., : 1985) dikutip dalam Tjiptono (2000)

1. Bukti langsung (tangibles), terdiri dari :

a. Peralatan dan perlengkapan pendukung pelayanan memadai 
b. Tersedianya fasilitas pendukung (tempat parkir, TV, bacaan, dll)

c. Penampilan karyawan yang rapi.

2. Kehandalan (reliability), terdiri dari :

a. Ketepatan dan kecepatan waktu pelayanan

b. Kesesuaian janji yang ditawarkan

c. Pemberian pelayanan yang tidak membeda-bedakan masyarakat.

3. Daya tanggap (responsiveness), terdiri dari :

a. Pelayanan melalui telepon

b. Kesigapan karyawan dalam menyelesaikan masalah

4. Jaminan (assurance), terdiri dari :

a. Keramahan dan kesopanan karyawan dalam melayani masyarakat

b. Dapat dipercaya dan memberikan rasa aman

c. Kehandalan dan pengalaman para karyawan.

5. Perhatian (emphaty), terdiri dari :

a. Cepat dan tanggap dalam menyelesaikan keluhan masyarakat

b. Memberikan perhatian secara khusus kepada setiap masyarakat

c. Dapat berkomunikasi yang baik dengan masyarakat.

\section{PEMBAHASAN DAN IMPLIKASI}

a. Kondisi Infrastruktur

Lingkup data ruas jalan pada pekerjaan ini meliputi seluruh wilayah Kota Blitar yang terdiri dari 3 kecamatan. Total panjang jalan di Kota Blitar adalah 265.723,3 meter, dengan jumlah ruas jalan sebanyak 823. Jenis perkerasan dibedakan atas aspal sepanjang236.928,2meter $\quad(89,16 \%)$, beton/ rabat sepanjang 19.041 meter
$(7,17 \%)$, paving sepanjang 9.327 meter $(3,51 \%)$ dan yang masih berupa jalan tanah/ belum diperkeras sepanjang 425 meter $(0,16 \%)$.

b. Pemeliharaan Infrastruktur

Pemeliharaan infrastruktur jalan dan jembatan melalui pembentukan satgas dengan memanfaatkan Media Sosial dan SMS Center sebagai sarana pengaduan masyarakat di DPUPR Kota Blitar sebagai bentuk komunikasi yang lebih efektif dengan memanfaatkan teknologi internet dan aplikasi komunikasi yang berkembang di masyarakat. Dengan demikian diharapkan satgas dapat dengan cepat dan tepat menindaklanjuti kerusakan yang ada di lapangan.

Alur Proses Pengaduan

a.Proses Penyampaian Pengaduan

Masyarakat

Proses penanganan Laporan Pengaduan

Masyarakat melalui Media Sosial Facebook

Laporan pengaduan masyarakat tentang kerusakan jalan dan jembatan yang masuk di Facebook Page Satgas Pemeliharaan Jalan Kota Blitar akan diberitahukan secara otomatis ke smartphone operator, kemudian operator akan menyampaikan kepada Project Leader dan Koordinator Pelaksana Satgas Pemeliharaan Jalan untuk dilakukan identifikasi dan rencana tindak lanjut penanganan kerusakan. Proses penanganan laporan pengaduan masyarakat melalui media sosial Facebook dapat dilihat pada bagan berikut:

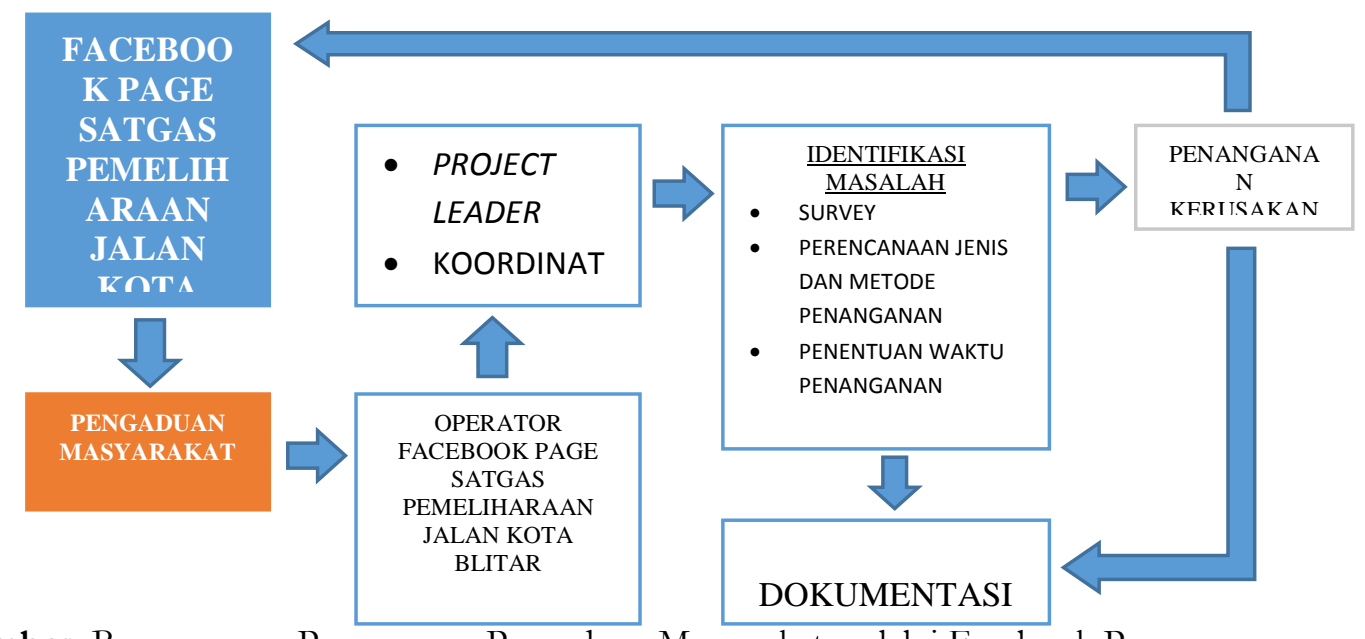

Gambar Bagan proses Penanganan Pengaduan Masyarakat melalui Facebook Page 


\section{Proses penanganan Laporan Pengaduan Masyarakat melalui SMS Center}

Setelah mendapatkan SMS terusan (forward), Project Leader dan Koordinator Pelaksana Satgas akan melakukan koordinasi dengan Satgas Pemeliharaan Infrastruktur Jalan untuk melakukan identifikasi dan rencana tindak lanjut penanganan kerusakan. Setelah dilakukan survey lapangan selanjutnya akan ditentukan jenis penanganan, metode penanganan dan penentuan waktu penanganan.

Proses penanganan laporan pengaduan masyarakat melalui SMS Center dapat dilihat pada bagan berikut:

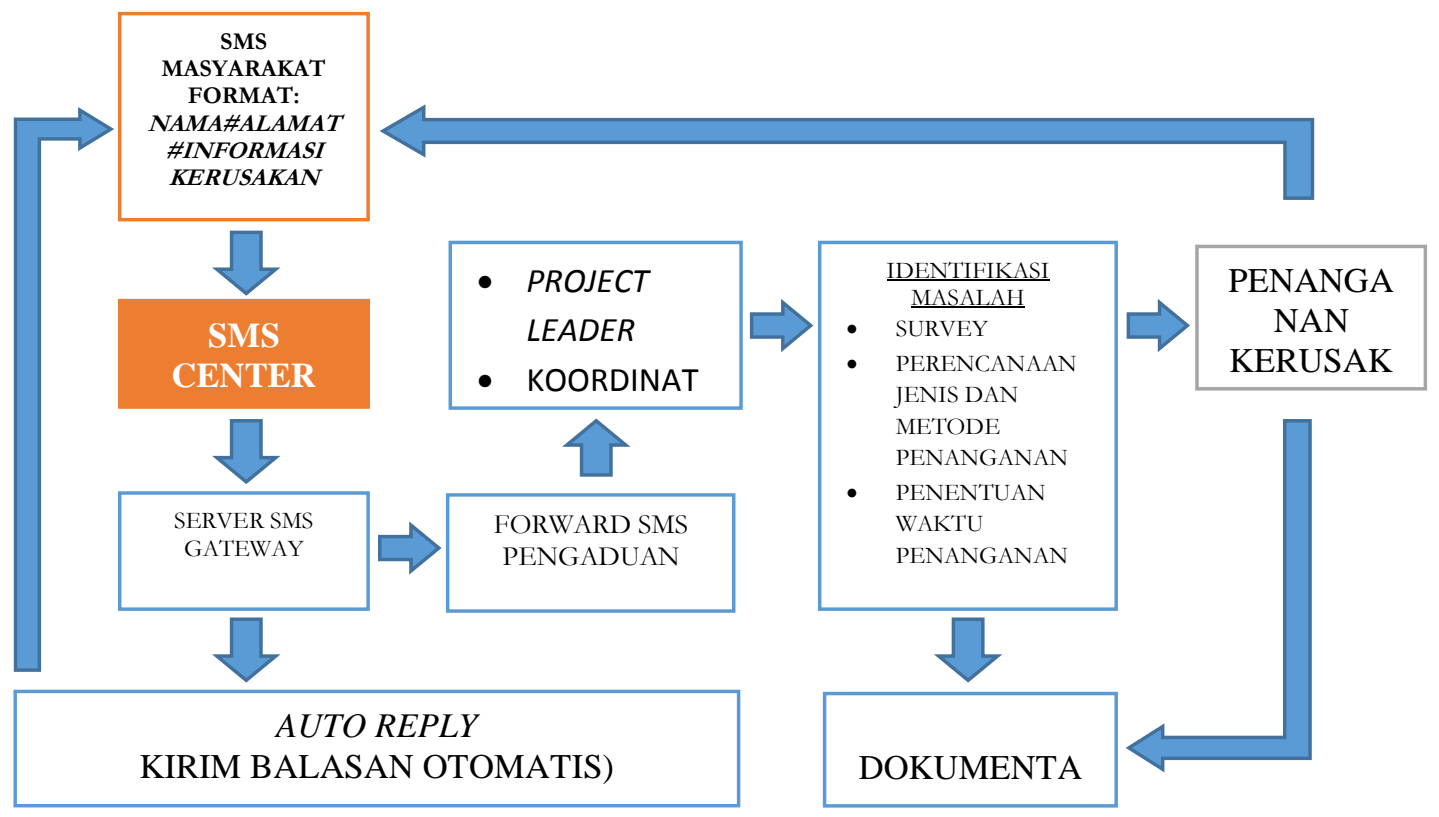

Pembahasan

\section{Hasil Hipotesa}

Hipotesis yang akan diuji: Terdapat pengaruh secara simultan (bersama-sama) kualitas pelayanan yang terdiri dari Keandalan, Jaminan, Bukti Fisik, Empati, dan Daya Tanggap terhadap kepuasan masyarakat.

Hasil uji $F$ pada penelitian ini dapat dilihat pada tabel 4 berikut ini:

\begin{tabular}{|ll|r|r|c|c|}
\multicolumn{7}{|c|}{ ANOVA $^{\text {a }}$} \\
Model & $\begin{array}{r}\text { Sum of } \\
\text { Squares }\end{array}$ & df & F & Sig. \\
\hline 1 Regression & 68.985 & 5 & 3.966 & $.003^{\mathrm{b}}$ \\
& Residual & 250.485 & 72 & & \\
\multicolumn{1}{|l|}{ Total } & 319.469 & 77 & & \\
\hline
\end{tabular}

a. Dependent Variable: Total_Y

b. Predictors: (Constant), Total_X1, Total_X2, Total_ Total_X4 Total_X5

Dan hasil uji $\mathrm{F}$ diperoleh nilai $\mathrm{F}$ hitung sebesar 3,966 dan angka signifikasi (P value) sebesar 0,003, dengan tingkat signifikasi 95\% (a=0,05). Angka signifikasi $(\mathrm{P}$ value) sebesar $0,003<0,05$. Atas dasar perbandingan tersebut, maka Ho ditolak berarti variabel Keandalan, Jaminan, Bukti Fisik, Empati, dan Daya Tanggap mempunyai pengaruh yang signifikan secara simultan (bersama-sama) terhadap variabel kepuasan masyarakat.

Pengujian secara Parsial (Uji t ) Hipotesis yang akan diuji: Terdapat pengaruh secara parsial kualitas pelayanan yang terdiri dari Keandalan, Jaminan, Bukti Fisik, Empati, dan Daya Tanggap terhadap kepuasan pelanggan. Tabel Uji Partial (t). Berdasarkan hasil uji $\mathrm{t}$ (tabel 5) dapat dijelaskan Variabel Empati Angka signifikansi (P Value) pada variabel empati sebesar 0,021 $<0,05$ artinya Ho ditolak. Hal ini berarti variabel empati secara parsial mempunyai pengaruh yang signifikan terhadap variabel kepuasan masyarakat.

Koefisien Determinasi (R2)

Koefisien determinasi (R2) diperoleh nilai Adjusted R Square adalah sebesar 0.161. Hal ini dapat diartikan bahwa variabel independen (Keandalan, Jaminan, Bukti Fisik, Empati dan Daya Tanggap) dapat 
menjelaskan variabel dependen (Kepuasan masyarakat) sebesar $16 \%$ sedangkan sisanya diterangkan oleh faktor lain yang tidak teliti.

\section{Impilkasi Penelitian}

Penelitian ini dapat diimplikasikan pada

DPUPR, sebagaimana berikut :

1. Pemeliharaan infrastruktur jalan dan jembatan melalui pembentukan satgas dengan memanfaatkan Media Sosial dan SMS Center sebagai sarana pengaduan masyarakat di Dinas Pekerjaan Umum dan Perumahan Kota Blitar dapat dikembangkan lagi dengan berbagai bentuk komunikasi yang lebih efektif dengan memanfaatkan teknologi internet dan aplikasi komunikasi yang berkembang di masyarakat. Dengan demikian diharapkan satgas dapat dengan cepat dan tepat menindaklanjuti kerusakan yang ada di lapangan.

2. Manfaat bagi Pemerintah Kota Blitar dengan terbentuknya satgas untuk meningkatkan kualitas pelayanan kepada masyarakat berupa pemeliharaan jalan dan jembatan secara cepat,tepat dan akurat.

3. Manfaat bagi masyarakat adalah dapat melakukan akses informasi yang terpercaya, kekinian dan akurat serta dapat meningkatkan partisipasi terhadap pemeliharaan jalan dan jembatan di Kota Blitar.

\section{KESIMPULAN}

Berdasarkan hasil penelitian dan analisa yang telah dilakukan mengenai pengaruh kualitas pelayanan terhadap kepuasan masyarakat, maka diperoleh beberapa kesimpulan yang dapat menjawab rumusan masalah dalam penelitian ini.

1. Kualitas Pelayanan melalui media sosial dan SMS center

Berdasarkan hasil analisis deskriptif kualitas melalui media sosial dan sms center DPUPR termasuk dalam kategori baik. Ini artinya kualitas melalui media sosial dan SMS center mendapatkan penilaian positif dan kesan yang baik di hati pelanggan.

2. Kepuasan masyarakat terhadap kinerja DPUPR

Berdasarkan hasil analisis deskriptif kepuasan masyarakat pengaduan masalah infrastruktur melalui media sosial dan sms center dan penangganan oleh Stagas Infrastruktur DPUPR masuk dalam kategori sangat baik.

3. Pengaruh Kualitas Pelayanan secara Simultan terhadap Kepuasan Masyarakat menunjukan bahwa variabel Jaminan, Bukti Fisik, Empati, dan Daya Tanggap secara simultan (bersama-sama) mempunyai pengaruh yang signifikan terhadap kepuasan masyarakat.

4. Pengaruh Kualitas Pelayanan secara parsial terhadap Kepuasan masyarakat pengaduan masalah infrastruktur melalui media sosial dan SMS center dipengaruhi oleh empati.

\section{DAFTAR PUSTAKA}

Moenir, Drs, H, A, S. 2006. "Manajemen Pelayanan Umum Di Indonesia".Jakarta: Bumi Aksara

Sinambela, Litjan Poltak. 2006. Reformasi Pelayanan Publik. Jakarta: BumiAksara

Sugiyono. 2011.Metode Penelitian Administrasi. Bandung: Alfabeta.

Alandari, Firman. 2013.Jurnal Ilmu Pemerintahan. Peran Sistem Informasi Manajemen Berbasis Komputer Dalam Meningkatkan Pelayanan Publik Di Lingkungan Kantor Bupati Kabupaten Berau.

Universitas Mulawarman Majid, Hasbi. 2013. Jurnal Ilmu Pengetahuan dan Teknologi. Pelayanan Informasi Perizinan Berbasis Electronic Government Pada Kantor Pelayanan Administrasi Perizinan Kota Makassar.

lain: Universitas YAPIS Papua Lain -

http://birokrasi.kompasiana.com/2013/03/ 25/layanan-perizinan-lewat-smsgateway-di-makassar-dan-barru545231.html diakses pada 23 Januari 2015.

http://seputarsulawesi.com/news-13920pemkot-makassar-dorong-pelayananperizinan-melalui-sms.html diakses pada 19 Februari 2015

usu.ac.id diakses oktober 2014 http://www.scribd.com/WIKEDIAH-ANJARYA diakses oktober 2014 http://www.wikipedia.com diakses oktober 2014 